\title{
Age is not associated with increased surgical complications in patients after laparoscopic sleeve gastrectomy
}

\author{
Emil Jędrzejewski, Maciej Liszka, Marcin Maciejewski, Piotr K. Kowalewski, Maciej Walędziak, Krzysztof Paśnik, \\ Michat R. Janik
}

Department of General, Oncologic, Metabolic and Thoracic Surgery, Military Institute of Medicine, Warsaw, Poland

Videosurgery Miniinv 2018; 13 (1): 82-87

DOI: https://doi.org/10.5114/wiitm.2017.69129

\begin{abstract}
Introduction: Age is considered as a risk factor in bariatric surgery. The observation was made on the basis of results from studies where patients underwent different type of surgery, but laparoscopic sleeve gastrectomy (LSG) was not among them. It is necessary to reevaluate the association of age with adverse events in the group of patients after LSG. Aim: To investigate the association of age with surgery-related adverse events in patients after LSG.

Material and methods: Retrospective analysis of medical data was performed. The study involved 345 patients who underwent LSG in our institution between January 2013 and December 2014. The patients were subdivided by age into four groups according to quartiles. In 30-day follow-up adverse events were evaluated. We considered the presence of the following events as the endpoint of our study: death, medical events and surgical events.

Results: In general, we observed adverse events in 36 (10.4\%) patients. The mortality rate in our study was $0.59 \%$. Nineteen events were surgical and 18 medical. In 1 patient a surgical event was associated with a medical event. Bleeding was the most common surgical event and was observed in 17 (4.9\%) cases. Age was not associated with surgical events $(O R=1.032,95 \% \mathrm{Cl}: 0.991-1.075, p=0.33)$ or medical events (OR=0.997, 95\% Cl: 0.956-1.039, $p=0.89)$.

Conclusions: The LSG is a safe bariatric procedure with low mortality. Bleeding is the most frequent surgical complication. Our findings suggest that age is not associated with increased risk of surgical or medical adverse events after $L S G$.
\end{abstract}

Key words: complications, bariatric surgery, sleeve gastrectomy, age.

\section{Introduction}

The effectiveness of bariatric surgery has been proven in many studies [1, 2]. This field of surgery has evolved since the 1990s. New procedures have gained popularity. Considering the latest update about worldwide bariatric surgery, laparoscopic sleeve gastrectomy (LSG) has become the most popular procedure $[3,4]$. Laparoscopic sleeve gastrectomy is relatively simple. Its rising popularity led to introduction of LSG to older patients [5]. However, the procedure is also associated with serious surgical complications such as bleeding or staple line leak. Age is considered a risk factor in bariatric surgery. Yet the observation was made on the basis of results from studies where patients underwent different type of surgery, but LSG was not amongst them $[6,7]$. Therefore it is necessary to reevaluate the association of age with adverse events in LSG.

\section{Aim}

The aim of the study was to investigate the association of age with surgery-related adverse events in patients after LSG.

\section{Address for correspondence}

Michał R. Janik, Department of General, Oncologic, Metabolic and Thoracic Surgery, Military Institute of Medicine, 128 Szaserów St, 04-141 Warsaw, Poland, phone: +48 602780 960, e-mail: janiken@gmail.com 


\section{Material and methods}

We performed a retrospective analysis of medical data. The study involved 345 patients who underwent LSG in our institution between January 2013 and December 2014. All patients underwent LSG performed by a team of high volume bariatric surgeons (over 50 LSG procedures per year).

\section{Surgical technique}

During laparoscopic sleeve gastrectomy, 75-80\% of the greater curvature was resected, forming a sleeve-shape stomach. Resection was started from approximately 3 to $7 \mathrm{~cm}$ above the pylorus. The short gastric vessels and the greater curvature ligaments were separated to the left diaphragmatic crus. A $36 \mathrm{Fr}$ bougie was used to calibrate the sleeve. A laparoscopic stapler was introduced and fired along the length of the bougie until the angle of His was reached. A gold (Echelon, Ethicon Endosurgery) or violet cartridge was used for the first two firings and blue for the rest (Covidien, Mansfield, MA). The resected part of the stomach was removed by one of the $12-\mathrm{mm}$ ports. In some cases we reinforced the staple line with a running suture when there was bleeding which could not be stopped by clipping [8]. A blue dye solution test was performed in every case to detect possible intraoperative leakage. A drain was placed alongside the staple line. A bariatric surgeon (over 50 LSG procedures per year) was involved in every procedure. Each patient underwent a blue dye solution test on the first postoperative day. If no leakage was detected, then an oral diet was resumed. The patient was discharged on the second day.

\section{Demographic data}

Mean preoperative BMI was $47.7 \pm 7.4 \mathrm{~kg} / \mathrm{m}^{2}$. The obesity-related comorbidities were: arteria hy- pertension (AHT) (49\%), type 2 diabetes (T2DM) (24\%), dyslipidemia (10\%), and obstructive sleep apnea (6\%). The mean age of patients was $41.8 \pm 11.4$ (range: 18-68). The patients were subdivided by age into four groups according to quartiles (Table I).

Possible adverse events were evaluated in a 30day follow-up. We considered the presence of the following events as the endpoint of our study: death, medical events and surgical events. The surgical events included leakage, bleeding and sleeve stenosis. Medical events included rhabdomyolysis, thromboembolism and respiratory failure. We defined bleeding as a drop in hemoglobin level with associated hypovolemic shock requiring surgical revision. Rhabdomyolysis was defined as an increase of creatine kinase level (CK) of more than 1,000 IU/I [9]. Thromboembolism consisted of deep venous thrombosis (DVT) or pulmonary embolism (PE). Respiratory failure was defined by mechanical ventilation used in the postoperative period.

\section{Statistical analysis}

Statistical analysis was performed using SAS software, University Edition (SAS Institute Inc., Cary, NC, USA). To compare continuous variables the Mann-Whitney $U$ test and Student's t-test were used when appropriate. The prevalence of endpoints was compared using the $\chi^{2}$ test and Fisher's exact test. Logistic regression and univariate analysis were used to assess the influence of age on the presence of adverse events. Statistical significance was set at $p<0.05$.

\section{Results}

The groups were comparable regarding body mass index (BMI), gender and comorbidities, including hypertension, dyslipidemia and obstructive sleep

Table I. Age groups of LSG patients

\begin{tabular}{|lcccccc|}
\hline $\begin{array}{l}\text { Age groups, } \\
\text { [years] }(n)\end{array}$ & BMI [kg/m²] & $\begin{array}{c}\text { Gender } \\
\text { female/male) }^{\text {NS }}\end{array}$ & $\begin{array}{c}\text { Hypertension, } \\
n(\%)^{\mathrm{NS}}\end{array}$ & $\begin{array}{c}\text { Diabetes } \\
\text { type II, } n(\%)^{*}\end{array}$ & $\begin{array}{c}\text { Dyslipidemia, } \\
n(\%)^{\mathrm{NS}}\end{array}$ & $\begin{array}{c}\text { Obstructive } \\
\text { sleep apnea, } \\
n(\%)^{\mathrm{NS}}\end{array}$ \\
\hline I: $18-33(92)$ & $49.4 \pm 7.5$ & $54 / 38$ & $38(41)$ & $15(16)$ & $6(6)$ & $4(4)$ \\
\hline II: 34-41 (86) & $47.5 \pm 6.1$ & $43 / 43$ & $40(46)$ & $17(20)$ & $11(13)$ & $8(9)$ \\
\hline III: 42-49 (82) & $46.2 \pm 6.6$ & $40 / 42$ & $49(60)$ & $27(33)$ & $12(15)$ & $4(5)$ \\
\hline IV: $\geq 50(85)$ & $48.1 \pm 7.8$ & $42 / 43$ & $42(49)$ & $24(29)$ & $6(7)$ & $5(6)$ \\
\hline
\end{tabular}

${ }^{*}$ Distribution of diabetes type II was statistically significant, ${ }^{\text {NS}}$ no statistical significance. 
apnea. There was a statistically significant difference in prevalence of T2DM among age groups. We observed higher prevalence of diabetes in age groups III and IV (Table I).

In general, we observed adverse events in 36 (10.4\%) patients. Nineteen events were surgical and 18 medical. Bleeding was the most common surgical event and was observed in $17(4.9 \%)$ cases. We observed a higher risk of bleeding in the group of older patients in comparison to the younger patients (Tables II and III). The increase was clinically significant. However, age was not a risk factor for bleeding in univariate analysis (Tables III, IV). In one patient bleeding was associated with rhabdomyolysis. Sleeve stenosis was present in $2(0.6 \%)$ cases. We did not observe any case of leakage in our material. The difference in surgical adverse events amongst age groups was not statistically significant. However, higher prevalence of bleeding in the elderly was clinically significant (Table II).

Eighteen events were medical. The most common medical event was rhabdomyolysis $(n=16$; $4.6 \%)$. In 2 cases rhabdomyolysis was followed by respiratory failure. We observed $2(0.58 \%)$ cases of thromboembolism. Both cases were severe. The first case was followed by respiratory failure. The second case was followed by sudden cardiac arrest and was fatal. The mortality rate was $0.29 \%$. On $\chi^{2}$ analysis of complications, no significant differences were present between age groups (Table II).

\section{Group I}

Group I comprised 92 patients between 18 and 33 years old, 38 (41\%) males and 54 (59\%) females, with preoperative BMI $49.4 \pm 7.5 \mathrm{~kg} / \mathrm{m}^{2}$. The AHT was observed in $38(41 \%)$ patients. The T2DM was present in $15(16 \%)$ patients. Six (6\%) patients had dyslipidemia and in 4 (4\%) patients obstructive sleep apnea was diagnosed (Table I).

In group I we observed 7 (7.6\%) events. Two were surgical and 5 were medical. Surgical events included 2 cases of bleeding from the staple line $(2.1 \%)$. Medical events included 4 cases of rhabdomyolysis after surgery $(4.3 \%)$ and 1 case of thromboembolism, which resulted in respiratory failure. No other events were observed (Table II).

Table II. Incidence of complications in the four age groups

\begin{tabular}{|c|c|c|c|c|c|c|c|c|c|}
\hline \multirow{3}{*}{$\begin{array}{l}\text { Age group } \\
\text { [years] }(n)\end{array}$} & \multicolumn{4}{|c|}{ Surgical event, $n(\%)^{\mathrm{NS}}$} & \multicolumn{4}{|c|}{ Medical event, $n(\%)^{\mathrm{NS}}$} & \multirow{3}{*}{$\begin{array}{c}\text { Number of } \\
\text { patients } \\
\text { with } \\
\text { endpoints, } \\
n(\%)^{\mathrm{NS}}\end{array}$} \\
\hline & \multicolumn{3}{|c|}{ Number of events } & \multirow{2}{*}{$\begin{array}{l}\text { Number } \\
\text { of cases }\end{array}$} & \multicolumn{3}{|c|}{ Number of events } & \multirow{2}{*}{$\begin{array}{l}\text { Number } \\
\text { of cases }\end{array}$} & \\
\hline & Bleeding & Early leak & Stenosis & & $\begin{array}{l}\text { Thrombo- } \\
\text { embolism }\end{array}$ & $\begin{array}{l}\text { Rhabdo- } \\
\text { myolysis }\end{array}$ & $\begin{array}{l}\text { Respiratory } \\
\text { failure }\end{array}$ & & \\
\hline I: 18-33 (92) & $2(2.2)$ & 0 & 0 & $2(2.2)$ & $1(1.1)$ & $4(4.3)$ & $1(1.1)^{\star}$ & $5(5.4)$ & $7(7.6)$ \\
\hline II: 34-40 (86) & $3(3.5)$ & 0 & $1(1.2)$ & $4(4.6)$ & 0 & $5(5.8)$ & $1(1.2)^{*}$ & $5(5.8)$ & $9(10.5)$ \\
\hline III: 41-49 (82) & $4(4.9)$ & 0 & $1(1.2)$ & $5(6.1)$ & $1(1.2)^{\star \star}$ & $2(2.4)^{8}$ & 0 & $3(3.7)$ & $7(8.5)$ \\
\hline$I V: \geq 50(85)$ & $8(9.4)$ & 0 & 0 & $8(9.4)$ & 0 & $5(5.9)$ & $1(1.2)^{*}$ & $5(5.9)$ & $13(15.3)$ \\
\hline Total (345) & $17(4.9)$ & 0 & $2(0.58)$ & $19(5.5)$ & $2(0.58)$ & $16(4.6)$ & $3(0.9)$ & $18(5.2)$ & $36(10.4)$ \\
\hline $\begin{array}{l}\text { Fisher's exact } \\
\text { test } p \text {-value }\end{array}$ & 0.168 & $x$ & 0.484 & 0.205 & 0.735 & 0.708 & 1.000 & 0.917 & 0.380 \\
\hline
\end{tabular}

${ }^{*}$ Complication secondary to primary medical adverse event, \&1 case of rhabdomyolysis was associated with bleeding, ${ }^{* *}$ fatal case, ${ }^{\text {NS}}$ no statistical significance.

Table III. Odds ratio for bleeding in different age groups

\begin{tabular}{|c|c|c|c|c|}
\hline \multicolumn{5}{|c|}{ Estimates for bleeding } \\
\hline Effect & Odds ratio & $95 \%$ & limits & $P$-value \\
\hline Group 1 vs. 4 & 0.214 & 0.044 & 1.037 & 0.0556 \\
\hline Group 2 vs. 4 & 0.348 & 0.089 & 1.359 & 0.3418 \\
\hline Group 3 vs. 4 & 0.494 & 0.143 & 1.707 & 0.5992 \\
\hline
\end{tabular}




\section{Group II}

Group II consisted of 86 patients between 34 and 41 years old, 43 (50\%) males and 43 (40\%) females, with preoperative BMI $47.5 \pm 6.1 \mathrm{~kg} / \mathrm{m}^{2}$. The AHT was observed in 40 (46\%) patients. T2DM was present in 17 (20\%) patients. Eleven (13\%) patients had dyslipidemia and in 8 (9\%) patients obstructive sleep apnea was diagnosed (Table I).

Nine events were observed in group 2 (10.5\%). Four (4.6\%) events were surgical and included 3 (3.5\%) cases of bleeding and 1 (1.2\%) case of sleeve stenosis. Five (5.8\%) events were medical - in those cases, rhabdomyolysis was diagnosed. In 1 (1.2\%) case rhabdomyolysis was followed by respiratory failure.

\section{Group III}

Group III was made up of 82 patients between 42 and 50 years old, 42 (51\%) males and 40 (49\%) females, with preoperative BMI $46.2 \pm 6.6 \mathrm{~kg} / \mathrm{m}^{2}$. The AHT was observed in 49 (60\%) patients. The T2DM was present in 27 (33.\%) patients. Twelve (15\%) patients had dyslipidemia and in 4 (5\%) patients obstructive sleep apnea was diagnosed (Table I).

In this age group we observed events in 7 (8.5\%) patients. Five of these events were surgical and included 4 (4.9\%) cases of bleeding and 1 (1.2\%) case of sleeve stenosis. In 1 case rhabdomyolysis was associated with bleeding. There were 2 primary medical events including 1 case of rhabdomyolysis and 1 case of thromboembolism, which led to a fatal outcome.

\section{Group IV}

Group IV comprised 85 patients aged over 50 years old, 43 (51\%) males and 42 (49\%) females, with preoperative BMI $48.1 \pm 7.8 \mathrm{~kg} / \mathrm{m}^{2}$. The AHT was observed in 42 (49\%) patients. The T2DM was present in 24 (29\%) patients. Six (7\%) patients had dyslipidemia and 5 (6\%) patients suffered from obstructive sleep apnea (Table I).

In this age group we observed presence of endpoints in 13 (15.3\%) patients. Considering the surgical events, there were $8(9.4 \%)$ cases of staple-line bleeding. Five of 13 events were medical and all involved rhabdomyolysis. In 1 case rhabdomyolysis was followed by respiratory failure. No other endpoints were observed.
Table IV. Univariate analysis of complications and age

\begin{tabular}{|c|c|c|c|}
\hline Variable & Odds ratio & $\begin{array}{c}95 \% \\
\text { confidence } \\
\text { interval }\end{array}$ & $P$-value \\
\hline Overall events: & 1.015 & $0.985-1.046$ & 0.335 \\
\hline Surgical events: & 1.032 & $0.991-1.075$ & 0.132 \\
\hline Bleeding & 1.035 & $0.992-1.081$ & 0.115 \\
\hline Stenosis & 1.002 & $0.887-1.131$ & 0.967 \\
\hline Medical events: & 0.997 & $0.956-1.039$ & 0.887 \\
\hline Thromboembolism & 0.978 & $0.863-1.109$ & 0.732 \\
\hline Rhabdomyolysis & 0.999 & $0.956-1.044$ & 0.979 \\
\hline Respiratory failure & 0.978 & $0.883-1.084$ & 0.675 \\
\hline Death & 1.025 & $0.863-1.217$ & 0.778 \\
\hline
\end{tabular}

\section{Discussion}

The mortality rate in our study was $0.59 \%$. We observed 1 fatal case due to a thromboembolic event after surgery. The findings of our study revealed no statistically significant difference in prevalence of adverse events after laparoscopic sleeve gastrectomy between different age groups. The data suggest that age is not associated with increased risk of surgery-related complications. However, in detailed analysis of the adverse events, we observed a high risk of bleeding in the group of older patients in comparison to the younger ones. In our opinion this observation might result from the influence of confounders. This needs to be investigated in further studies.

The LSG is a bariatric procedure, introduced in 1990 as an alternative to distal gastrectomy with the duodenal switch procedure to reduce the rate of complications [10]. Its safety and efficacy have been proven [2]. However, LSG is associated with some serious perioperative complications. The main complications in the early postoperative period are postoperative bleeding and the occurrence of a gastric leak. The rates of bleeding and leakage are about $1-5 \%$ [11]. Approximately $3 \%$ of patients after LSG require reoperation due to surgical adverse events [12]. Other adverse events after LSG are typical for bariatric patients and include rhabdomyolysis, thromboembolism and respiratory failure $[13,14]$.

According to the latest report about the status of bariatric surgery, LSG is one of the most frequently 
performed bariatric procedures in the world [4]. With growing experience in laparoscopic techniques, it becomes clear that advanced age is not an absolute contraindication for many minimally invasive procedures, including bariatric surgery [15]. Elderly patients may benefit from bariatric surgery $[16$, 17]. However, the authors of the papers mentioned above emphasize that in the case of older adults, surgery should be performed in a high-volume or experienced center. The recommendation resulted from the fact that age is a commonly reported risk factor in studies of bariatric surgery $[7,18,19]$. However, the studies were based on data from different types of procedures. Our study is one of the first to investigate the association of age and adverse events in patients after LSG. The results of our study are opposite to the findings reported in the aforementioned papers. Likewise, in a recently published paper by Aminian et al., multivariate analysis on a large sample did not reveal any association between age and morbidity after LSG [20]. New studies, including ours, suggest that age has no influence on surgery-related events in patients after LSG.

Our study has several limitations. There are some potential confounders which were not considered in the study. One of them is the reinforcement of the staple line. This information was not gathered in our study. Usually we use running sutures or clipping of the staple line to prevent postoperative bleeding. However, we lack reliable data comparing the methods mentioned above in terms of bleeding. Another potential confounder is the fact of previous abdominal surgery. We included only those patients in whom LSG was the primary bariatric procedure. Yet, we did not collect data regarding previous abdominal procedures, such as cholecystectomy or laparotomy. The presence of adhesions after abdominal surgery influences the difficulty of the procedure and may result in higher risk of postoperative complications. These data should be collected in future studies. Moreover, we recommend focusing on the most frequently surgical complication after LSG - bleeding. Lastly, we did not collect data regarding the distance from the pylorus. This should be included as another potential confounder.

\section{Conclusions}

The LSG is a safe bariatric procedure with low mortality. Bleeding is the most frequent surgical complication. Our findings suggest that age is not associated with increased risk of surgical adverse events after LSG. This method is equally safe in different age groups and may be applied in older patients.

\section{Conflict of interest}

The authors declare no conflict of interest.

\section{References}

1. Buchwald H, Avidor Y, Braunwald E, et al. Bariatric surgery: a systematic review and meta-analysis. JAMA 2004; 292: 1724-37.

2. Colquitt J, Pickett K, Loveman E, et al. Surgery for weight loss in adults (Review). Cochrane Database Syst Rev 2014; 8: CD003641.

3. Janik MR, Stanowski E, Paśnik K. Present status of bariatric surgery in Poland. Videosurgery Miniinv 2016; 11: 22-5.

4. Angrisani L, Santonicola A, Iovino P, et al. Bariatric Surgery Worldwide 2013. Obes Surg 2015; 25: 1822-32.

5. McGlone ER, Bond A, Reddy $M$, et al. Super-obesity in the elderly: is bariatric surgery justified? Obes Surg 2015; 25: 1750-5.

6. Finks JF, English WJ, Carlin AM, et al. Predicting risk for venous thromboembolism with bariatric surgery: results from the Michigan Bariatric Surgery Collaborative. Ann Surg 2012; 255: 1100-4.

7. DeMaria EJ, Portenier D, Wolfe L. Obesity surgery mortality risk score: proposal for a clinically useful score to predict mortality risk in patients undergoing gastric bypass. Surg Obes Relat Dis 2007; 3: 134-40.

8. Kwiatkowski A, Janik MR, Paśnik K, et al. The effect of oversewing the staple line in laparoscopic sleeve gastrectomy: randomized control trial. Videosurgery Miniinv 2016; 11: 149-55.

9. Chakravartty S, Sarma DR, Patel AG. Rhabdomyolysis in bariatric surgery: a systematic review. Obes Surg 2013; 23: 1333-40.

10. Frezza EE. Laparoscopic vertical sleeve gastrectomy for morbid obesity. The future procedure of choice? Surg Today 2007; 37: 275-81.

11. Shikora SA, Mahoney CB. Clinical benefit of gastric staple line reinforcement (SLR) in gastrointestinal surgery: a meta-analysis. Obes Surg 2015; 25: 1133-41.

12. Frezza EE, Reddy S, Gee LL, et al. Complications after sleeve gastrectomy for morbid obesity. Obes Surg 2009; 19: 684-7.

13. The Longitudinal Assessment of Bariatric Surgery (LABS) Consortium. Perioperative safety in the longitudinal assessment of bariatric surgery. N Engl J Med 2009; 361: 557-68.

14. Major P, Wysocki M, Pędziwiatr M, et al. Can the obesity surgery mortality risk score predict postoperative complications other than mortality? Videosurgery Miniinv 2016; 11: 247-52.

15. Efron DT, Bender JS. Laparoscopic surgery in older adults. J Am Geriatr Soc 2001; 49: 658-63.

16. Murr MM, Siadati MR, Sarr MG. Results of bariatric surgery for morbid obesity in patients older than 50 years. Obes Surg 1995; 5: 399-402.

17. Sugerman HJ, DeMaria EJ, Kellum JM, et al. Effects of bariatric surgery in older patients. Ann Surg 2004; 240: 243-7. 
18. Finks JF, Kole KL, Yenumula PR, et al. Predicting risk for serious complications with bariatric surgery: results from the Michigan Bariatric Surgery Collaborative. Ann Surg 2011; 254: 633-40.

19. Ramanan B, Gupta PK, Gupta H, et al. Development and validation of a bariatric surgery mortality risk calculator. J Am Coll Surg 2012; 214: 892-900.

20. Aminian A, Brethauer SA, Sharafkhah M, et al. Development of a sleeve gastrectomy risk calculator. Surg Obes Relat Dis 2015; 11: 758-64.

Received: 21.04.2017, accepted: 21.06.2017. 